\title{
As independências do Haiti e da América Hispânica na Correspondência de Thomas Jefferson (1791-1822)
}

\author{
Marcos Sorrilha Pinheiro ${ }^{1}$
}

\begin{abstract}
RESUMO: Considerando que Thomas Jefferson (1743-1826) foi um dos responsáveis pela elaboração da Declaração de Independência dos EUA, pareceu-nos lícito averiguar qual foi a sua reação diante das emancipações das demais colônias do continente americano. Para tanto, tomamos como fonte o epistolário jeffersoniano buscando em sua correspondência trechos em que ele compartilhou impressões ou opiniões a respeito de tais episódios. Dentro desta proposta, o artigo dividiu-se em duas partes: a primeira responsável pela análise das epístolas em que Jefferson discutiu a independência do Haiti; a segunda tem como enfoque as independências da América Espanhola. Mais do que um simples objeto de curiosidade, a leitura das cartas possibilita perceber a pertinência de algumas das mais importantes preocupações que circundavam o imaginário político norte-americano daquele momento: a consolidação da Nação e o seu papel diante do continente em relação aos demais países europeus.
\end{abstract}

Palavras-Chave: Correspondência de Thomas Jefferson; Independência do Haiti; Independências da América hispânica; Relações Diplomáticas entre EUA e nações europeias.

ABSTRACT: Considering Thomas Jefferson (1743-1826) as one of those responsible for writing the Declaration of Independence of the USA, it seemed legitimate to inquire his reaction about the emancipation of the other colonies in the American Continent. To conduct this research, we had set as our source the Jeffersonian epistolary, seeking in his correspondence quotes where he shared impressions or opinions about such episodes. Following this aim, this article has been divided into two parts: the first one is responsible for the analysis of the letters in which Jefferson discussed the independence of Haiti; the second has as focus the independence of Spanish America. More than a simple object of curiosity, reading the letters allows us realize the relevance of some of the most important concerns that surrounded the American politician imaginary at that moment: the consolidation of the US Nation and its role on the continent compared to other Europeans countries.

Key Words: Latin American Independence; Correspondence; Thomas Jefferson Correspondence; Haitian Independence; Hispanic America Independence; USA and Europe Diplomacy.

Artigo recebido em: 11/03/2016

Artigo aprovado para publicação em: 07/04/2017

\footnotetext{
${ }^{1}$ Doutor em História pela Unesp/Franca; Professor Assistente Doutor da Unesp/Franca onde desenvolve o projeto de pesquisa intitulado Liberdade e Igualdade: o vocabulário das independências em Thomas Jefferson e Simón Bolívar (1763-1821); Endereço para correspondência: Av. Eufrásia Monteiro Petráglia, 900, CEP 14.409160 (Departamento de História); e-mail: msorrilha@ franca.unesp.br
}

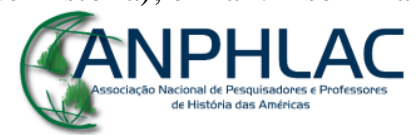

Revista Eletrônica da ANPHLAC, ISSN 1679-1061, №. 22, p. 60-85, Jan./Jun., 2017.

http://revista.anphlac.org.br 


\title{
Apresentação
}

\begin{abstract}
Quando, no curso dos acontecimentos humanos, torna-se necessário a um povo dissolver os laços políticos que o ligavam a outro, e assumir, entre os poderes da Terra, posição igual e separada, a que lhe dão direito às leis da natureza e às do Deus da natureza, o respeito digno para com as opiniões dos homens exige que se declarem as causas que os levam a essa separação. (Declaração de Independência dos EUA)
\end{abstract}

Existem alguns personagem históricos que possuem suas biografias vinculadas a determinados eventos. Por mais que se produza a constante revisão de suas vidas e obras, não é possível dissocia-las destes eventos. Thomas Jefferson (1743-1826) é um exemplo disso: apesar de sua notável trajetória política e de seu reconhecido gosto pela ciência, foi a sua participação na elaboração do documento de proclamação de independência, de 04 de julho de 1776, que o marcou decisivamente. Este dado aparece em destaque na lápide que guarda o seu túmulo e, para além da morte, invade o imaginário norte-americano até os dias de hoje.

De qualquer modo, tal sina nos serviu de premissa para o desenvolvimento de uma breve pesquisa que, aqui, apresenta seus resultados. Explicamos: pareceu-nos legítimo fazer uma investigação a respeito de quais foram as reações de Thomas Jefferson diante dos eventos que marcaram as emancipações das demais colônias do continente americano. Para levar adiante esta averiguação, estabelecemos nosso foco sobre o epistolário jeffersoniano ${ }^{2}$, buscando em sua correspondência trechos onde ele compartilhou (com diversos interlocutores) impressões ou opiniões a respeito de tais episódios.

Há que se esclarecer que a pesquisa foi dividida em duas etapas que, por sua vez, também delimitaram os objetos analisados dentro do epistolário. Primeiramente dedicamos nossa atenção sobre a independência do Haiti. Trata-se do primeiro processo de independência deflagrado após a consolidação da emancipação norte-americana e que, por vários motivos que demonstraremos a seguir, colocaram os Estados Unidos e

\footnotetext{
${ }^{2}$ Todas as cartas analisadas neste artigo foram retiradas da coletânea organizada por Paul Ford (1905) sob o título de The Works of Thomas Jefferson, dividida em 12 volumes. Sabemos que ela não possui todas as cartas confeccionadas por Jefferson em sua longa trajetória pública, porém, trata-se de uma das compilações que com mais recorrência é mencionada em trabalhos dedicados ao estudo do terceiro presidente dos EUA. As únicas cartas que não foram mobilizadas junto à coletânea de Ford são aquelas endereçadas a Alexander von Humboldt. Essas se encontram disponíveis em sua íntegra em um artigo organizado por Helmut Terra em 1959.
}

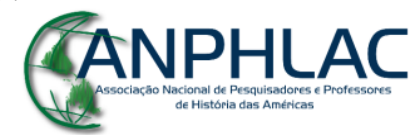

Revista Eletrônica da ANPHLAC, ISSN 1679-1061, №. 22, p. 60-85, Jan./Jun., 2017.

http://revista.anphlac.org.br 
seus políticos no centro das discussões sobre o mesmo. O período que cobre este evento vai de 1791 a 1806 e, nele, foram encontradas 38 correspondências em que a Independência do Haiti aparecia claramente mencionada.

Porém, justamente por se espalharem por um lapso temporal considerável, entendemos que fosse plausível delimitar a existência de três blocos de correspondências relativos aos diferentes momentos em que se encontrava o litígio entre a colônia francesa e sua metrópole. Da mesma forma, ao fazermos tal recorte, foi possível perceber os reposicionamentos de Jefferson diante da contenda à medida que sua posição dentro da administração pública atingia novos patamares, inclusive quando ele chegou à Presidência (1801-1809). Obviamente que não estamos insinuando que os cargos tenham determinado as opiniões de Jefferson, mas que as novas posições o colocaram diante de informações, dilemas e necessidade de tomadas de decisões que contribuíram para a elaboração de (re)interpretações sobre o evento.

A segunda etapa de nossa investigação foi dedicada à análise das cartas que trataram especificamente das independências hispano-americanas. Neste momento, foi possível localizar 14 correspondências em que o tema das emancipações roubou-lhe a atenção. Quando nos debruçamos sobre a leitura das mesmas, e as colocamos em comparação com àquelas que mencionavam a contenda haitiana, podemos demarcar duas diferenças principais: a) Jefferson não ocupou cargos públicos ao longo de quase toda a troca de cartas, fazendo com que os comentários sobre este evento (ou eventos) se assemelhassem a uma espécie de curiosidade sem maiores repercussões; b) os Estados Unidos não foram diretamente envolvidos, fazendo com que o resultado da empreitada emancipacionista não interferisse sobremaneira no juízo de Jefferson sobre o evento.

Talvez, essas duas diferenças tenham contribuído para que as opiniões de Jefferson sobre o tema das independências na América Hispânica tenham sido diversas em relação aos dois casos. De outra forma, levantam-nos, também, algumas questões sobre o quanto a ideia de equilíbrio hemisférico, que geralmente se atribui à Doutrina Monroe (PECEQUILO, 2005), não seria algo que estivesse presente desde os primórdios da formação dos EUA. Em outras palavras, a noção de que a estabilidade política dos Estados Unidos dependesse do equilíbrio de seus vizinhos de continente é algo que apresenta alguns traços na correspondência jeffersoniana, principalmente

\section{CANPHLAC}

Revista Eletrônica da ANPHLAC, ISSN 1679-1061, №. 22, p. 60-85, Jan./Jun., 2017.

http://revista.anphlac.org.br 
quando ele se põe a discutir o Haiti. Afinal, como veremos, um dos temores de Jefferson era o de que a vitória dos escravos na ilha francesa contribuísse para a dissolução da jovem nação norte-americana, seja por meio da influência que tal evento poderia causar sobre seus escravos, impulsionando-os à rebelião, ou com o surgimento de um movimento separatista dos senhores de escravos, insatisfeitos com os possíveis apoios do Governo Americano aos insurgentes na ilha caribenha. Ainda que não tenhamos chegado a conclusões sobre tais questionamentos, esperamos que as linhas a seguir possam também auxiliar futuros pesquisadores na busca por respostas aos mesmos.

\section{O Haiti (1791-1806)}

A independência do Haiti é um dos episódios mais importantes para a História do continente americano. Seu caráter insurrecional e o fato de ter contado com a participação maciça de escravos despertaram as atenções de amplos setores da sociedade política na América. Para alguns autores (LYNCH, 2004), este evento foi decisivo para os destinos emancipatórios da região hispano-americana. Seguindo esta linha de raciocínio, o temor de que um levante "plebeu" ocorresse em outros cantos do continente teria antecipado os movimentos independentistas por parte da classe colonial governante, os criollos.

Assim, mais do que uma inspiração, a independência do Haiti servira como uma advertência. Ao mesmo tempo, ficaria impregnada como uma lembrança de que, para o desespero dos senhores de escravos, os cativos eram aptos a comandar uma insurreição capaz de transformar o status quo social, dando liberdade aos cativos e aniquilando os seus donos. A este sentimento de insegurança e temor, deu-se o nome de haitianismo, fenômeno muito comum, principalmente entre parte da elite brasileira do século XIX, mas, também, junto aos aristocratas da Virgínia, como veremos mais adiante. ${ }^{3}$

Outro fato importante a se destacar no processo de separação do Haiti de sua antiga metrópole, a França, é que esta foi a primeira independência a ocorrer na América Latina e a segunda em todo o mundo, segundo os preceitos modernos de

\footnotetext{
${ }^{3}$ Sobre o termo haitianismo, existe uma ampla bibliografia que analisou este tema. Apenas a título de sugestão, indicamos o livro A América Latina na Época Colonial (LOCKHART; SCHWARTZ, 2002).

\section{GANPHLAC}

Revista Eletrônica da ANPHLAC, ISSN 1679-1061, №. 22, p. 60-85, Jan./Jun., 2017.

http://revista.anphlac.org.br 
nação. Antes de Santo Domingo, apenas os Estados Unidos haviam encarado o desafio de proclamar a autonomia política e administrativa de seu território. Conforme sublinhamos, foi justamente esta peculiaridade que nos levou a uma questão até certo ponto elementar: como os EUA receberam a notícia da independência do Haiti? Mais precisamente: o que Thomas Jefferson, senhor a quem se atribui a redação da declaração de independência de 1776, "pensou" ao ver o "seu" exemplo seguido por outros povos do continente?

A resposta, ainda que não surpreendente, foi curiosa. Diferente do que se poderia esperar, os EUA não apenas não encararam com bons olhos tal emancipação como, no governo do próprio Jefferson, recusaram-se a reconhecer a autonomia da ilha e a legitimidade de seu novo governo. O reconhecimento estadunidense viria somente sessenta anos depois, após a deflagração de sua Guerra Civil (1861-1865). Isto posto, nossa atenção esteve voltada apenas às cartas produzidas no período que compreende o início das hostilidades na ilha, em 1791, até a promulgação da Lei do Embargo, que proibiu o comércio entre os Estados Unidos e o Haiti, em 1806, consagrando o não reconhecimento de sua independência.

Ao longo de todo este período, Jefferson escreveu algo em torno de 800 cartas com diferentes propósitos e para diversos destinatários. É bem verdade que um número elevado delas tratou de questões pertinentes ao conflito bélico travado nos mares do Caribe por navios mercantes americanos, principalmente no enfrentamento dos mesmos com "piratas" de outras nacionalidades. (KILMEADE; YAEGER, 2015) Outras tantas, dedicaram-se à compreensão dos novos desenhos do cenário pós-revolucionário francês. Ambos os assuntos estão diretamente ligados ao imbróglio haitiano. No entanto, interessava-nos somente as cartas que faziam menção direta ao Haiti.

Assim, entre todas as correspondências, identificamos 38 cartas que atendiam a esta especificação. Justamente por isso, nossa análise limitou-se a elas. De antemão, aproveitamos para fazer uma advertência: Jefferson ocupou três diferentes cargos públicos ao longo do período observado e, por isso, suas opiniões, muitas vezes, aparecem atreladas ao papel que ele desempenhava em cada um desses momentos. É importante que isso seja ressaltado não apenas por uma questão metodológica. Na realidade, o que nos chamou a atenção foi o fato de que, em suas cartas, Jefferson apenas mencionou este acontecimento nos momentos em que ocupou cargos públicos.

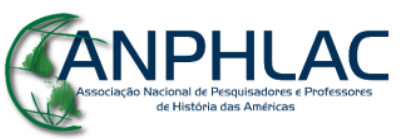

Revista Eletrônica da ANPHLAC, ISSN 1679-1061, №. 22, p. 60-85, Jan./Jun., 2017. http://revista.anphlac.org.br 
Por exemplo, entre 1794 e 1796, período em que esteve ausente dos postos de poder, uma única carta fez menção aos problemas verificados nas "ilhas francesas". Ainda assim, trata-se de um documento escrito três meses após a sua saída da Secretaria de Estado, em 1794, e endereçada à James Madison, seu interlocutor recorrente e representante da Virgínia na câmara dos deputados. (FORD, 1905c, p. 141-143)

Uma primeira e imprecisa avaliação que podemos depreender dessa questão é: apesar de formalmente não envolver os Estados Unidos, Jefferson tratou o levante no Haiti como uma questão de Estado; como um problema que dizia respeito às autoridades estadunidenses. Não apenas por envolver cidadãos norte-americanos, como os comerciantes de suprimentos e armas para as ilhas do Caribe, mas também, pois, como veremos mais a frente, ele entendia que seus desdobramentos poderiam afetar diretamente o equilíbrio de forças e a frágil unidade interna de seu país.

Diante de tal observação, não poderia ser diferente que dividíssemos a correspondência de Jefferson, também em três diferentes grupos, seguindo a cronologia de seus cargos no poder. Desta feita, o primeiro bloco vai de 1791 a 1793, momento em que ocupou o cargo de Secretário de Estado no governo de George Washington. Neste intervalo, foram encontradas cerca de 18 cartas. O segundo bloco, com 11 cartas, vai de 1797 a 1799, quando foi vice-presidente dos Estados Unidos na administração de John Adams. O terceiro e último bloco de correspondências fica restrito aos anos de $1800 \mathrm{a}$ 1806 e compreende o primeiro e parte de seu segundo mandato como presidente. Temos, neste intervalo, 8 cartas. ${ }^{4}$ Feitas essas considerações iniciais, passemos à apresentação da correspondência.

A primeira epístola escrita por Jefferson que tratou especificamente da ilha de Santo Domingo data de 24 de março de 1791 e teve como destinatária sua filha Martha Jefferson. Nesta epístola, o recém-empossado Secretário de Estado dos EUA comentava sobre os desdobramentos da Revolução Francesa e como isso acarretou no descontrole observado em suas colônias insulares. Conforme escreveu,

Suas ilhas, mas mais particularmente St. Domingo e Martinica, estão envolvidas em uma guerra civil horrível. Nada pode ser mais preocupante do que a situação de seus habitantes, tendo seus escravos sido chamados para a

\footnotetext{
${ }^{4}$ Somando esses três blocos à mencionada carta escrita em 1794, temos as 38 cartas mencionadas anteriormente.

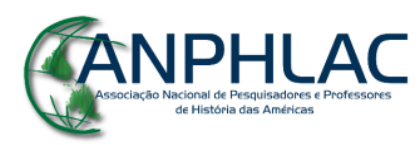

Revista Eletrônica da ANPHLAC, ISSN 1679-1061, №. 22, p. 60-85, Jan./Jun., 2017.

http://revista.anphlac.org.br
} 
ação, formando uma terrível força motriz, absolutamente ingovernável. (FORD, 1905a, p. 225)

À medida que os acontecimentos foram ficando cada vez mais graves, o interesse de Jefferson sobre o assunto também aumentava, bem como a importância dada ao evento. Isso se verifica não apenas no conteúdo das cartas, mas, também, na "qualidade" de seus destinatários. Por conta disso, entre 24 de novembro de 1791 e 07 de dezembro de 1793, 17 cartas foram endereçadas a 11 interlocutores diferentes ${ }^{5}$, mas com o mesmo objetivo: ressaltar a importância do envio de socorro e suporte aos colonos franceses das ilhas, auxiliando-os na resistência ao levante.

Assim sendo, em todas as conversas travadas nas correspondências, Jefferson deixou evidente o respeito e admiração que possuía pelos franceses, antigos aliados políticos e, justamente por isso, o temor de que os europeus interpretassem tais ajudas como uma intromissão aos seus assuntos internos. Em uma carta endereçada ao Marechal Lafayette, em 16 de junho de 1792, por exemplo, o então Secretário de Estado dos Estados Unidos confessava o medo de que a França tivesse "ciúmes" do auxílio mencionado, dizendo que ela deveria sentir-se afortunada por possuir um parceiro que pudesse socorrê-la e que vivesse tão próximo de seus territórios na América. (FORD, 1905b, p. 109-111)

Além de mantimentos, armamentos e dinheiro destinados aos colonos, outro assunto discutido nas missivas dizia respeito ao asilo político a ser ofertado aos colonos brancos fugitivos do conflito. Em 26 de maio de 1793, em nova correspondência enviada à sua filha, Jefferson mencionou o assassinato de aristocratas pelas mãos de escravos na ilha de Guadalupe. Nela, alertou sobre a possibilidade de que ela possuísse algum amigo entre as vítimas e que o governo norte-americano deveria resgatar e receber alguns dos aristocratas franceses de Santo Domingo em seu território.

Dois meses depois, este assunto voltou à tona em uma correspondência enviada a James Monroe, àquele momento, senador dos Estados Unidos pelo Estado da Virgínia. Em 14 de julho de 1793, Jefferson ponderou: “a situação dos fugitivos de St.

\footnotetext{
${ }^{5}$ Os destinatários eram: William Short, Agente Diplomático norte-americano na França; George Washington, presidente dos EUA; Lafayette, militar francês e amigo de Jefferson; Gouverneur Morris, ministro norte-americano na França; Jean Baptiste Ternat, ministro da França nos EUA; James Madison, deputado pela Virgínia; James Monroe, Senador; Edmond-Charles Genet, embaixador da França nos EUA; Martha Jefferson, filha; George Hammond, embaixador da Inglaterra nos EUA; e o Gabinete de Decisões do Presidente.
}

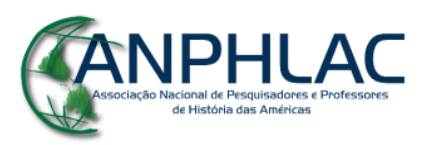

Revista Eletrônica da ANPHLAC, ISSN 1679-1061, №. 22, p. 60-85, Jan./Jun., 2017.

http://revista.anphlac.org.br 
Domingo (aristocratas como eles são) clama por piedade e caridade. Nunca uma tragédia foi tão profundamente apresentada aos sentimentos do homem." (FORD, 1905b, p. 449) ${ }^{6}$

A citação não deixa dúvida. Ainda que nesta mesma epístola Jefferson ressaltasse a necessidade de que os Estados Unidos se mantivessem neutros em relação ao conflito, fica evidente a sua aproximação a favor da causa dos senhores de escravos de Santo Domingo, sublinhando sua condição aristocrática. A propósito, o que se pode notar neste primeiro bloco de cartas é justamente o posicionamento de Jefferson em favor da França, sempre cauteloso quanto aos interesses dos europeus e partilhando de uma solidariedade de classe para com os colonos das ilhas Caribenhas.

Tal posicionamento fica nítido na correspondência enviada a Madison em 03 de abril de 1794 e anteriormente mencionada. Ao se afastar da Secretaria de Estado dos Estados Unidos, por conta de seu famoso desentendimento com Alexander Hamilton, Jefferson escreveu ao amigo e deputado dizendo que era fundamental que se "declarasse igualmente à Inglaterra e França, que essas ilhas deveriam se manter subordinadas à França." (FORD, 1905c, p. 142)

Depois de três anos afastado de um cargo oficial, Jefferson reapareceu no cenário público em 1797, agora ocupando o posto de vice-presidente da República. Três meses depois de sua posse, a ilha de Santo Domingo ressurgiu como tema de suas cartas. Trata-se de uma correspondência datada de 21 de junho de 1797 e endereçada a Elbridge Gerry, um político de Massachusetts. Nela, Jefferson analisava a imprudência de se entrar em uma guerra contra a França e a Inglaterra, uma vez que isto poderia interferir diretamente nos interesses dos comerciantes norte-americanos que atuavam na região do Caribe. (FORD, 1905c, p. 313-315)

É importante perceber que o hiato de pouco mais de três anos entre uma correspondência e outra nos coloca diante de um contexto completamente oposto àquele verificado anteriormente na carta a Madison de 1794. Diferentemente do apoio incondicional aos franceses contra os rebeldes, Jefferson pondera, desta feita, sobre um provável conflito entre os EUA e as demais potências europeias devido à nova reconfiguração do mapa do Caribe. Isto se explica pela alteração do cenário político

\footnotetext{
${ }^{6}$ Este assunto também é tratado na última carta endereçada ao gabinete de decisões do Presidente dos Estados Unidos em 07 de dezembro de 1793, dias antes de Jefferson deixar o governo.
}

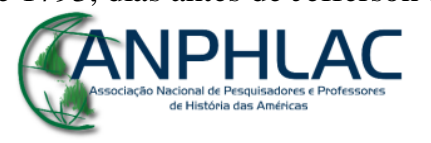

Revista Eletrônica da ANPHLAC, ISSN 1679-1061, №. 22, p. 60-85, Jan./Jun., 2017.

http://revista.anphlac.org.br 
internacional em duas ordens: a) o aumento do recrudescimento das relações entre franceses e ingleses em solo europeu; b) a vitória iminente de Toussaint Louverture em Santo Domingo.

Da mesma forma que o apoio incondicional à França marca o primeiro bloco de cartas, o temor de que a atuação indireta de americanos no conflito caribenho produzisse um confronto bélico entre os EUA e aquela potência europeia é algo que se destaca no segundo grupo de epístolas. Isto porque, diferentemente do que solicitavam os diplomatas franceses, os mercadores americanos continuaram fazendo comércio com a ilha de Santo Domingo, mesmo após a expulsão de quase todos os senhores de terras de seu território. Esclarecendo: diversamente daquilo que ocorreu nos anos anteriores, agora, os comerciantes estadunidenses levavam armas e mantimentos aos rebeldes e não mais aos aristocratas, fato que despertou o descontentamento das autoridades francesas que respondiam com ataques e aprisionamentos de seus navios mercantes.

Em resposta às agressões em alto mar, uma série de leis prevendo a suspensão do comércio com a França e o apoio aos esforços do líder haitiano Toussaint Louverture começaram a tramitar no Congresso. Na visão de Jefferson, ao tomar tais atitudes, o parlamento norte-americano dava motivos para que a França declarasse guerra aos EUA, conforme comentou com James Madison em uma missiva enviada em 05 de fevereiro de 1799. (FORD, 1905d, p. 32-35)

Seis dias depois, em 11 de fevereiro, o vice-presidente escreveu para Aaron Burr, importante militar nas campanhas pela independência norte-americana, comentando sobre um possível ataque francês ao sul do país. (FORD, 1905d, p. 37-39) O desembarque de tropas francesas em território americano não era algo a ser descartado, uma vez que, ainda que nunca tenha sido oficializada, entre os anos de 1798 e 1800, nos mares do Caribe, desenhou-se uma "verdadeira" guerra entre Estados Unidos, França, Inglaterra e Espanha que ficou conhecida como Quasi War. (HICKEY, 1982) $\mathrm{Na}$ realidade, ao longo desses anos, os EUA continuaram praticando a sua política de suposta neutralidade, evitando decretar um apoio formal a qualquer dos lados na contenda, mas permitindo que seus comerciantes continuassem a fazer seus negócios com os insurgentes. A diferença nesse caso é que, ao contrário do que se viu nos primeiros anos, neste momento, os aristocratas já não representavam uma força de

\section{GANPHLAC}

Revista Eletrônica da ANPHLAC, ISSN 1679-1061, №. 22, p. 60-85, Jan./Jun., 2017.

http://revista.anphlac.org.br 
resistência aos rebeldes que, por sua vez, passaram a ser quem recorria aos fornecedores norte-americanos como forma de abastecer o seu estoque de armas e mantimentos.

O temor de Jefferson era que este "conflito não oficial", protagonizado principalmente por navios mercantes e a marinha francesa, resultasse em algo maior, colocando em risco não apenas a estabilidade do país, como também a ocupação do território da Louisiana que paulatinamente vinha sendo "colonizada" por plantadores de algodão norte-americanos. Quem mais lucrava com esse perigoso comércio com os rebeldes de Santo Domingo eram os comerciantes do norte do país. Justamente por isso, chama a atenção o fato de que duas cartas deste período tenham sido destinadas a políticos do norte, ambos de Massachusetts: Elbridge Gerry (FORD, 1905c, p. 283-288) e Rufus King (FORD, 1905d, p. 383-387), que, naquele momento, atuava como Ministro dos Estados Unidos na Inglaterra. ${ }^{7}$

De qualquer maneira, esse novo quadro de relações com a França resultou em um reposicionamento da presidência que, sob a administração de John Adams, passou a ser simpática à causa dos homens de Toussaint Louverture. Até mesmo a nomeação de um embaixador para a ilha foi discutida pelo senado, fato este que apareceu em duas correspondências escritas por Jefferson em 19 de fevereiro de 1799 e endereçadas a Edmund Plendeton, seu antigo amigo e importante jurista da Virgínia, e a James Madison, seu interlocutor predileto. (FORD, 1905d, p. 45-53) Nessa mudança de humores, o próprio Jefferson, naquela epístola enviada a Madison em 05 de fevereiro daquele ano, dizia ver com bons olhos uma possível separação da ilha de sua metrópole, desde que seguisse as bases do acordo informal feito entre Thomas Maitland (general britânico) e Toussaint Louverture. Conforme escreveu, "o tratado feito com eles por Maitland é (se for para que se separem da França) a melhor coisa para nós." (FORD, 1905d, p. 33) Mesmo assim, a ressalva sobre uma possível retaliação francesa nunca saiu de seu horizonte de preocupação.

O terceiro bloco de cartas é, de todos, o mais controverso para a nossa compreensão. Acreditamos que tal fato não se deva apenas por conta do novo posto ocupado pelo personagem analisado, a presidência da República, mas principalmente pelo cenário absolutamente complexo e difuso que se desenhou na primeira década do

\footnotetext{
${ }^{7}$ O próprio Aaron Burr, mencionado anteriormente, havia sido senador pelo estado de Nova York entre 1791 e 1797.
}

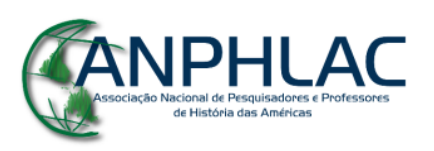

Revista Eletrônica da ANPHLAC, ISSN 1679-1061, №. 22, p. 60-85, Jan./Jun., 2017.

http://revista.anphlac.org.br 
século XIX. Tanto as variáveis internas quanto as externas tomaram rumos muito diferentes daqueles que vinham se desenhando no final da década anterior.

Por conta disso, a vitória iminente de Toussaint Louverture e o encaminhado reconhecimento norte-americano à independência de Santo Domingo - que apareceram no segundo grupo de cartas - ruíram diante dos influxos causados pela base eleitoral de Jefferson na Virgínia, das novas estratégias imperiais de Napoleão e da necessidade de se formalizar a compra de territórios na parte ocidental do continente, como a própria Louisiana. Todos esses elementos pesaram na decisão de Jefferson em defender a retomada da ilha de Santo Domingo por parte dos franceses, contrariamente ao que deixava transparecer no final de seu mandato como vice-presidente.

A correspondência que abre este terceiro bloco foi destinada a James Monroe, então governador da Virgínia, em 24 de novembro de 1801. Neste documento, encontramos um elemento novo e fundamental para compreendermos as ponderações que Jefferson possuía sobre um possível triunfo dos rebeldes em Santo Domingo: a escravidão ${ }^{8}$. Jefferson sempre temeu particularmente dois efeitos que poderiam resultar de uma vitória de Toussaint Louverture. O primeiro, de que a ilha se convertesse, segundo os seus dizeres, em uma espécie de "Nação de Piratas", replicando, em território americano, algo que ocorria com a Argélia, na África, naquele mesmo momento. Foi seguindo tal pensamento que o missivista se empenhou em convencer a França e a Inglaterra a se unirem contra as forças rebeldes de Santo Domingo, tão logo chegou à presidência.

O segundo efeito relacionava-se justamente à capacidade de o triunfo ser tomado como inspiração aos demais escravos que viviam em solo norte-americano. Aliás,

\footnotetext{
${ }^{8}$ A relação entre Thomas Jefferson e a escravidão é o tema mais abordado sobre a sua longa e controversa carreira política, principalmente a partir de meados da década de 1960, quando se começou a produzir uma revisão historiográfica a seu respeito. De um ávido defensor do fim do tráfico de escravos, fato destacado em seus rascunhos da Declaração de Independência, Jefferson entrou para a história como uma figura ambígua no trato deste tema, uma vez que jamais deu liberdade a seus próprios escravos. Além disso, mesmo quando advogou em prol da liberdade dos escravos, o tema da igualdade racial para Jefferson foi algo que não se verificou, sendo que, a seu ver, brancos e negros não possuíam as mesmas aptidões biológicas. No momento em que ocupava a presidência, Jefferson discutiu brevemente sobre a possibilidade de libertação de escravos, mas sempre fazendo uma ressalva: não seria possível que os libertos e antigos senhores vivessem na mesma localidade. Jefferson avaliava que o sentimento de vingança gerado pelos séculos de escravidão levaria a um conflito inevitável entre negros e seus antigos algozes. Justamente por isso, é possível encontrar em sua correspondência planos para que os libertos fossem enviados para países da África ou que se fosse criado um novo estado na América destinado apenas à população negra. Como veremos, até mesmo o Haiti foi visto como um possível destino aos libertos. Sobre Jefferson e escravidão, ver COHEN, 2000 e SCHWABACH, 2010.
}

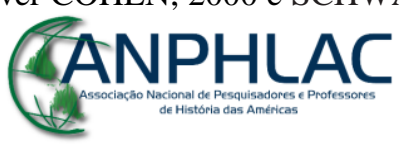

Revista Eletrônica da ANPHLAC, ISSN 1679-1061, №. 22, p. 60-85, Jan./Jun., 2017.

http://revista.anphlac.org.br 
durante todo o processo de independência do Haiti, isto foi algo que esteve na pauta dos escritos de Jefferson, mas não só. A própria chegada de refugiados negros em território norte-americano era algo que deveria ser considerado. Em uma carta enviada a um jurista da Virgínia, St. George Tucker, ainda em 1797, Jefferson discutia sobre qual deveria ser o destino dado aos "imigrantes de cor" que viessem das ilhas francesas para viver nos Estados Unidos. Segundo argumentava, era preciso encarar essa pergunta de modo que encontrassem uma resposta pacífica que contemplasse a "justiça, a política e a necessidade". Porém, mais do que tudo, era preciso resolver rapidamente essa questão, "pois se algo não for feito, e logo, nós seremos os assassinos de nossas próprias crianças.” (FORD, 1905c, p. 335)

A diferença entre esta carta de 1797 e aquela à Monroe, que abre o terceiro bloco de correspondências, de 1801, é que algo de concreto ocorreu entre elas. Em 1800, na Virgínia, uma suposta rebelião de escravos foi descoberta antes mesmo que fosse deflagrada. A insurgência vinha sendo organizada há mais de dois anos por Gabriel Prosser, um escravo. O evento, conhecido como Gabriel's Rebellion, externou o haitianismo dos senhores de escravos da Virgínia, que passaram a direcionar todos os seus cartuchos contra a política de aproximação aos rebeldes de Santo Domingo, como ocorrera no final do mandato de Adams. ${ }^{9}$

Voltando à carta endereçada a Monroe em 1801, Jefferson lamentou sobre as penas aplicadas aos negros após o julgamento de todos os envolvidos na mal fadada rebelião. Porém, mais do que isso, voltou a se questionar sobre quais atitudes deveriam ser tomadas para que brancos e negros libertos pudessem viver sem o perigo de que tais eventos como aquele se tornassem cada vez mais frequentes. Entre as saídas cogitadas, estava, inclusive, o envio dos escravos libertos a Santo Domingo, "onde os negros estão estabelecidos em uma soberania de fato, e se organizaram sob as leis regulares de governo." (FORD, 1905d, p. 318) ${ }^{10}$

\footnotetext{
${ }^{9}$ Mal comparando, este evento (Gabriel's Rebellion) teve efeito semelhante ao Levante dos Malês no Brasil, no sentido de promover uma espécie de consenso em torno do antiabolicionismo entre as elites detentoras de escravos. Sobre a rebelião liderada por Gabriel Prosser na Virgínia, ver EGERTON, 1993.

${ }^{10}$ Entre as várias saídas imaginadas por Jefferson nesta carta, estava: a compra de territórios na parte ocidental do continente americano e formar uma colônia específica para negros; o envio dos negros para outros territórios como a América portuguesa. Em outra carta, endereçada a Rufus King em 1802, sugeria que os negros fossem "repatriados" para a África em uma ação conjunta com a Serra Leoa Company. (FORD, 1905d, p. 383-387)
}

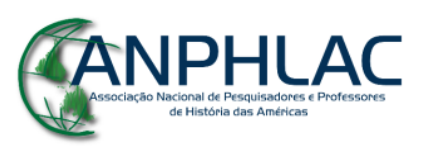

Revista Eletrônica da ANPHLAC, ISSN 1679-1061, №. 22, p. 60-85, Jan./Jun., 2017.

http://revista.anphlac.org.br 
Para além das reflexões sobre as políticas abolicionistas de Jefferson, esta carta nos permite concluir que, assim como afirmara em 1799, o presidente dos EUA realmente entendia que Santo Domingo havia se convertido em um Estado de Direito com "leis regulares de governo", atribuindo aos revoltosos a capacidade de se organizarem dentro de uma soberania de fato. No entanto, diferente desta afirmação contida na missiva, o que se viu foi justamente o oposto, pois, como sabemos, Jefferson nunca reconheceu oficialmente o Haiti como uma nação livre e soberana.

De qualquer maneira, ao que parece, a mal fadada rebelião da Virginia colocou Jefferson em rota de colisão com a antiga política de John Adams, mais próxima aos interesses haitianos. Por isso, seus primeiros atos enquanto presidente foram o de se aproximar dos diplomatas franceses que residiam nos Estados Unidos e tentar um novo acordo diplomático com a França, ainda que julgasse isso uma tarefa muito indigesta, conforme confidenciou a Livingston em carta escrita em 18 de abril de 1802. (FORD, 1905d, p. 363-368) Mesmo assim, aproveitando-se dos planos de Napoleão de reaver a ilha, Jefferson articulou junto ao diplomata francês, Louis André Pichon, uma reaproximação entre a França e os ingleses para que fosse empreendida uma ação conjunta das três nações contra Toussaint Louverture e seus homens. Tal ofensiva seria coordenada pelo General Leclerc em 1803. Da parte dos EUA, ficaria a responsabilidade de enviar barcos em socorro ao exército francês e a suspensão do comércio com os revoltosos. ${ }^{11}$

No entanto, antes que Leclerc e seus quarenta mil homens chegassem ao Caribe, tanto os norte-americanos quanto os ingleses acusaram a existência de um ruído de comunicação que colocou em desconfiança o acordo firmado entre as três nações e revelou aquilo que parecia ser o "real" plano de Napoleão com a expedição. Segundo se apurou, os franceses pretendiam reconquistar o Haiti em poucas semanas e, depois disso, usar o restante do contingente de soldados para desembarcar na Louisiana e tomar posse efetiva do território que, há muito tempo, vinha sendo ocupado por fazendeiros dos Estados Unidos. (MATTHEWSON, 1995)

Tal informação colocou os Estados Unidos e a França em lados opostos durante a expedição de Leclerc. Diferentemente do que previa o acordo informal, Jefferson não

\footnotetext{
${ }^{11}$ Sobre os acordos informais estabelecidos entre Jefferson e Pichon para a realização da expedição do General Leclerc, ver LOKKE, 1928.
}

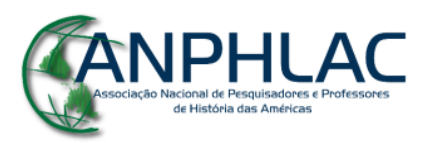

Revista Eletrônica da ANPHLAC, ISSN 1679-1061, №. 22, p. 60-85, Jan./Jun., 2017.

http://revista.anphlac.org.br 
enviou navios e também não suspendeu o comércio com os rebeldes. Isso tornou possível que, mesmo diante do aprisionamento de Toussaint Louverture, os insurgentes tivessem acesso a armas e mantimentos para continuar com sua luta emancipatória, agora sob a liderança do General Jean-Jacques Dessalines. Em outras palavras, não fosse a participação indireta dos EUA, talvez, os destinos da independência do Haiti não tivessem se definido a favor da causa separatista no ano seguinte, em 1804.

Porém, é preciso que se esclareça que o posicionamento de Jefferson neste episódio não ocorreu por conta de seu apoio aos habitantes de Santo Domingo, mas em defesa de seus interesses. Justamente por isso, tão logo chegou ao fim a malograda expedição liderada por Leclerc, o presidente reabriu negociações com a França para que se concretizasse a compra da Louisiana por parte dos norte-americanos. Apesar do negócio ser também do interesse da França, como forma de levantar fundos para suas campanhas militares na Europa, a reaproximação serviu para selar a paz entre as duas nações. Justamente por isso, entre as medidas tomadas para que tal negócio se efetivasse, encontra-se a aprovação da Lei do Embargo, de 1806, mas que tramitou no Congresso durante quase dois anos e foi votada por duas vezes.

Apenas a título de esclarecimento: a Lei do Embargo proibiu que qualquer navio que saísse dos Estados Unidos fizesse comércio com Santo Domingo e, mesmo aqueles que insistissem em fazê-lo clandestinamente, não teriam o respaldo federal quando atacados por navios de outras nações, como a própria França. Evidentemente que, por mais insipiente que fosse, a lei possuía uma justificativa para a sua proposição. Ocorre que, depois da chegada de Dessalines ao poder e da consolidação da separação de Santo Domingo da França, os conflitos na ilha não cessaram. Naquele momento, as tropas haitianas moveram-se na direção da segunda porção da ilha que ainda estava sob o domínio francês e governada pelo General Jean-Marie Ferrand.

Diante dessa situação de conflito, ao invés de reconhecer a legitimidade de Dessalines, Jefferson alegou que o Haiti não era uma nação soberana, mas um território francês em litígio com a sua metrópole e, por isso, os Estados Unidos não poderiam ajudar um grupo de homens subversivos, uma vez que o direito sobre as terras pertenciam ainda aos franceses. (MATTHEWSON, 1996)

Ao que parece, a postura bélica e até certo ponto "imperialista" de Dessalines, vislumbrando a unificação da ilha sob seu regime, foi muito mal recebida pela base de

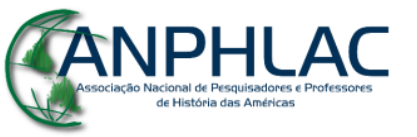

Revista Eletrônica da ANPHLAC, ISSN 1679-1061, №. 22, p. 60-85, Jan./Jun., 2017. http://revista.anphlac.org.br 
apoio de Jefferson, os escravagistas da Virgínia. Justamente por isso, foram eles que lideraram, com tanto fervor ideológico, a votação da Lei do Embargo aprovada em 1806, mesmo depois de ter sido recusada pelo Congresso no ano anterior. (MATTHEWSON, 1995)

Além disso, Jefferson se beneficiava desta questão para atingir outro objetivo declarado ainda na época da independência dos EUA: levar o país para além dos montes Apalaches e colonizar o território do hemisfério norte do continente americano. Porém, ainda que representasse um sinal de boa vontade para com os franceses, em troca da venda da Louisiana, parece-nos que a Lei do Embargo teve relação direta com a questão da escravidão. Não fosse por isso, ela não teria se mantido de maneira formal até a Guerra Civil, sendo derrubada apenas em 1863. Afinal, como sabemos, a polêmica em torno da escravidão foi algo que marcou este conflito.

Para além da questão da escravidão, este terceiro bloco não possui um posicionamento homogêneo de Jefferson diante da questão que possa nos servir como síntese para análise. Na realidade, ele deve ser divido em três "atos" diferentes e que seriam os seguintes. Entre 1801 e 1802, o tom é de receio para com os destinos da política externa francesa e os planos de Napoleão. ${ }^{12}$ Em 1802, antes mesmo de que se suspeitasse dos reais motivos da expedição de Leclerc, Jefferson escrevera para Livingston dizendo do seu temor de que a Louisiana fosse invadida por Napoleão, conforme já comentamos.

O segundo "ato" (1803-1804) é composto por correspondências a Monroe (enviado especial à França para a compra da Louisiana), James Madison (seu Secretário de Estado) e John Armstrong Jr (Senador pelo estado de Nova York). Todas as cartas tratam do recrudescimento dos conflitos entre a França e Santo Domingo após a chegada de Dessalines ao poder, mas, primordialmente, abordam a aquisição dos territórios franceses por parte do governo dos Estados Unidos.

O último "ato" (1805-1806) é composto por duas cartas onde o clima de tensão entre EUA e França já estava superado. Nelas, o missivista faz comentários sobre os franceses em tons mais amistosos a Thomas Paine, da mesma maneira que pede a

\footnotetext{
${ }^{12}$ Além das cartas enviadas a Monroe e Livingston, já mencionadas, uma terceira carta compõe este ato e estava endereçada a Rufus King, em 1802.
}

\section{GANPHLAC}

Revista Eletrônica da ANPHLAC, ISSN 1679-1061, №. 22, p. 60-85, Jan./Jun., 2017.

http://revista.anphlac.org.br 
Armstrong Jr., que agora ocupava o cargo de ministro americano na França, que advogasse em prol das boas relações entre França e EUA.

Neste sentido, este último bloco de cartas não possui um perfil único como os outros dois, conforme informamos. Por um lado, o posicionamento de Jefferson em relação ao processo de independência do Haiti se perde em meio a outros interesses e deixa de ser claro. Por outro, a avaliação sobre a França está evidente. Entre 1801 e 1806, as cartas demonstram o abandono de uma posição cautelosa para a adoção de novos laços de cooperação e irmandade diplomática consagrados pela compra da Louisiana e pela aprovação da Lei do Embargo. Por outro lado, a ambiguidade deste último bloco reforça aquilo que afirmamos sobre a influência dos cargos em seus posicionamentos a respeito da contenda, afinal, eles não eram determinantes em suas opiniões, mas colocavam-no diante de outras informações que o levavam a novas ações. Além disso, demonstram que as atitudes tomadas por Jefferson em relação ao conflito não seguiam um tipo de orientação filosófica ou um juízo moral sobre a legitimidade do mesmo. Ao contrário, por vezes, elas divergiam de sua opinião, como as cartas demonstram, seguindo o perfil de político pragmático que o caracterizou nos anos como presidente. Interessante notarmos que, no caso das independências hispano-americanas, Jefferson não ocupou nenhum posto junto à administração pública, o que pode ter-lhe dado mais liberdade para atuar como um "mero" observador interessado nos acontecimentos desenvolvidos ao sul do hemisfério. Ao mesmo tempo, não o colocam em conflito entre aquilo que pensava sobre o evento e aquilo que eventualmente ele teria feito. Sobre isso, é o que nos dedicaremos agora.

\section{As independências Hispano-americanas}

Neste segundo momento de análise da correspondência jeffersoniana, dedicaremos nossa atenção aos comentários feitos por ele sobre o processo emancipatório da América Hispânica. É correto que qualifiquemos tais escritos como “comentários", pois, diferentemente daqueles mencionados sobre o Haiti, esses se dão em um momento da vida do personagem em que ele não mais ocupava um cargo oficial. Conforme o próprio Jefferson advertiu, “eu não tomo mais partido em nenhum desses casos, para além de emitir minha opinião.” (FORD, 1905e, p. 96) Algo oposto ao que

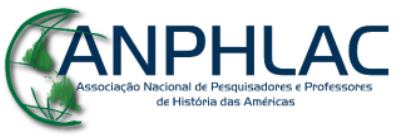

Revista Eletrônica da ANPHLAC, ISSN 1679-1061, №. 22, p. 60-85, Jan./Jun., 2017. http://revista.anphlac.org.br 
vimos no caso do Haiti, quando ele não apenas tinha que tomar partido, mas, efetivamente, agir politicamente.

De qualquer maneira, tal citação aparece na carta endereçada a James Monroe em 28 de janeiro de 1809. É nela, também, que encontramos a primeira menção às independências hispano-americanas. Naquele exato momento em que redigia a missiva, faltavam apenas cinco semanas para que o terceiro presidente dos EUA deixasse o cargo rumo à aposentadoria. Neste sentido, os acontecimentos que sucederiam a invasão de Napoleão Bonaparte à Espanha e o iminente confronto da França com a Inglaterra tornar-se-iam responsabilidades de seu sucessor.

De qualquer modo, tal qual já anunciamos, ainda que não fosse mais o responsável direto pelas ações de seu país, Jefferson não se furtou a emitir sua opinião. Neste caso em específico, vale ressaltar que a carta foi endereçada a Monroe, seu amigo e um dos principais destinatários encontrados no epistolário de Jefferson. Foi a ele, então, que Jefferson advertiu que os EUA se configuravam como um excelente aliado potencial para qualquer lado da contenda que então se desenhava na Europa entre franceses e ingleses.

Por conta disso, a decisão mais acertada, em sua opinião, era a de que o país não tomasse partido, evitando entrar em uma guerra e limitando-se a acordos comerciais com as partes. Afinal, caso não se envolvesse em conflitos continentais e não aumentasse os seus gastos abruptamente, no prazo de oito anos, o país pagaria suas dívidas, podendo aumentar os investimentos em infraestrutura ao ponto de se colocar em pé de igualdade com qualquer outra nação do mundo, inclusive militarmente.

De qualquer forma, essa visão isolacionista, recorrente nas estratégias diplomáticas dos EUA daquele período (PECEQUILO, 2005), não poderia ser confundida com uma alienação diante da realidade. Ao contrário, na visão de Jefferson a deposição de Fernando VII por Napoleão traria consequências diretas para as colônias espanholas da América e, desde que elas fossem favoráveis aos EUA, a neutralidade deveria ser utilizada como uma estratégia para esse fim. Vejamos como ele pontuou esta questão:

Bonaparte, tendo a Espanha sob seus pés, irá olhar imediatamente para as colônias espanholas e imaginar que nossa neutralidade pode ser comprada a

\section{GANPHLAC}

Revista Eletrônica da ANPHLAC, ISSN 1679-1061, №. 22, p. 60-85, Jan./Jun., 2017.

http://revista.anphlac.org.br 
baixo custo pela revogação das partes ilegais de seus decretos, oferecendo, possivelmente a Flórida como parte na barganha. (FORD, 1905e, p. 95-96) 13 $^{13}$

Nesse primeiro momento, a preocupação do então presidente era com a Flórida. Jefferson via no desarranjo da Coroa espanhola uma oportunidade de anexar formalmente aquele território ao seu país. Porém, mais do que isso, tal leitura do contexto deixava nítida a sua visão de que os confrontos desenvolvidos no Velho Mundo ressoariam inevitavelmente na América, algo que ficaria ainda mais evidente dois anos mais tarde, pois, como é sabido, em 1811, o movimento emancipatório do México e das colônias espanholas ao sul do equador já apresentavam os primeiros resultados concretos. (Cf. LYNCH, 2004) As juntas separatistas se organizaram nas principais cidades dos Vice-reinados espanhóis e os principais líderes começavam a se revelar.

Foi a partir de então, portanto, que o conteúdo das cartas de Jefferson se tornou mais específico, mudando o foco de sua atenção dos combates no velho continente para os levantes criollos no Novo Mundo. Sobre isso, destacamos duas cartas, uma endereçada a Alexander Von Humboldt, de 14 de abril de 1811 e outra a Du Pont de Nemours ${ }^{14}$, de 15 de abril de 1811 . O primeiro fato que nos chamou a atenção sobre as epístolas foi a proximidade em suas datas de envio, o que sugere a existência de um interesse genuíno de Jefferson no assunto. Conforme ele mesmo adverte a Humboldt, "é chegado o momento em que esses países se tornam interessantes para todo o mundo." (JEFFERSON apud TERRA, 1959, p. 791)

De qualquer maneira, ainda que o interesse fosse concreto, suas considerações ainda apareciam de forma muito prematuras e, talvez por isso, suas opiniões tenham sido formuladas tal qual hipóteses que se desenharam em formato de perguntas, conforme podemos observar:

Que tipo de governo se estabelecerá? Quanta liberdade eles podem suportar sem intoxicação? Seus chefes são suficientemente esclarecidos para formar um governo coeso, e seus povos para assistir a seus chefes? Importam-se o

\footnotetext{
${ }^{13}$ A oficialização de parte da Flórida (Flórida Ocidental) como um território Americano ocorreria um ano depois, em 1810, no governo de James Madison. Em 1819, a incorporação seria plena.

14 Pierre Samuel du Pont de Nemours era um interlocutor francês de Jefferson desde a época em que ele viveu na França, na década de 1780. Após regresso aos EUA, trocaram cartas esporádicas. Esta, em específico, foi enviada em resposta ao colega que lhe escrevera sete meses antes. Nela, o autor discorre a respeito do modelo de taxação norte-americano sobre a produção e produtos. A América Hispânica aparece como assunto paralelo.
}

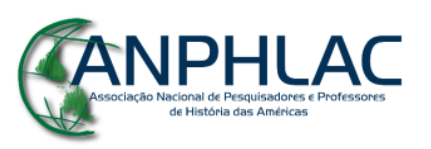

Revista Eletrônica da ANPHLAC, ISSN 1679-1061, №. 22, p. 60-85, Jan./Jun., 2017.

http://revista.anphlac.org.br 
suficiente para colocarem os seus índios domesticados em pé [de igualdade] com os brancos? Todas estas perguntas você pode responder melhor do que qualquer outro. (JEFFERSON apud TERRA, 1959, p. 791)

É preciso que façamos uma pausa nesta exposição para descrevermos um pouco mais sobre o destinatário de tais interrogações e a relação que ele estabelecia com Jefferson. A amizade entre Thomas Jefferson e Alexander Von Humboldt não era nova. A fama do norte-americano na França, por conta da independência dos EUA e de seu interesse pela ciência, era algo que já havia chamado a atenção da família Humboldt ainda na Europa. (PARET, 1993) Por conta disso, quando de sua viagem para a América em 1804, Alexander passou por Washington e foi recebido por importantes nomes da política norte-americana, incluindo o então presidente Thomas Jefferson. Como bem descreve Helmut Terra (1959, p. 786) em um artigo já bem antigo, este encontro não poderia ter sido mais providencial para o Chefe de Estado norteamericano, uma vez que ele ocorreu no exato momento em que o governo estadunidense realizava as tratativas de compra da Louisiana. Por isso, no ano de 1804, quatro correspondências foram trocadas entre os interlocutores, por onde informações sobre o relevo, o clima, a demografia e outros assuntos desta seara foram intercambiados. ${ }^{15}$ De certa maneira, "o apreço compartilhado pela ciência" e a "vontade de conhecer mais a fundo sobre a geografia do continente" aproximaram Jefferson de Humboldt. Ironias à parte, a verdade é que o cientista alemão encaminhou ao amigo americano versões dos volumes de seu livro intitulado Political Essay on the Kingdom of New Spain. Foi em uma das cartas de agradecimento pelo envio de tal material que Jefferson aproveitou de todo conhecimento que Humboldt possuía da Nova Espanha e de seus governantes para fazer aquelas indagações transcritas anteriormente.

De qualquer maneira, ainda que respeitasse a opinião do colega e reconhecesse o seu maior conhecimento sobre o assunto, Jefferson não esperou o retorno da réplica à sua carta para emitir um prognóstico sobre tal situação e arriscar algumas respostas a suas próprias perguntas. Juntamente com isso, apareceram previsões sobre os passos a serem adotados pelos líderes da emancipação hispano-americana:

\footnotetext{
${ }^{15}$ Segundo os materiais que utilizamos para este artigo, entre 1804 e 1813, Jefferson e Humboldt trocaram 12 correspondências.
}

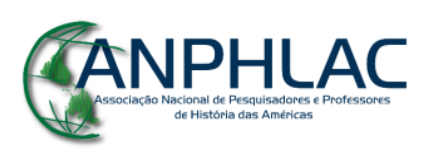

Revista Eletrônica da ANPHLAC, ISSN 1679-1061, №. 22, p. 60-85, Jan./Jun., 2017.

http://revista.anphlac.org.br 
Eu imagino que eles irão copiar as linhas gerais de nossa confederação e governo eletivo, abolir a distinção de grau, curvar o pescoço para seus sacerdotes e perseverar a intolerância. Sua maior dificuldade será na construção do seu Executivo. Eu suspeito que, apesar da experiência da França, e dos EUA, em 1784, eles vão começar com um Diretório e, quando os cismas inevitáveis nesse tipo de Executivo levá-los para outras situações, a grande questão que os acometerá será a se desejam substituir este Executivo, por um que seja eleito, por um período de anos, para a vida, ou um que seja hereditário. (JEFFERSON apud TERRA, 1959, p. 791-792)

Algo que se destaca nesse diagnóstico é o tom pessimista que o autor carrega em sua pena. Para ele, era inevitável que as independências das colônias espanholas resultassem na proliferação do despotismo naquela região. Ainda que isso não esteja claro na carta endereçada a Humboldt e tudo apareça no campo da especulação, sabemos que era exatamente isso o que Jefferson temia quando lemos a epístola destinada a Du Pont de Nemours e postada no dia seguinte. Conforme podemos ler no excerto a seguir: "temo que a ignorância degradante na qual seus sacerdotes e reis os afundaram incapacitem-nos de manter ou até mesmo reconhecer os seus direitos, e que muito sangue pode ser derramado em troca de pouca melhora em sua condição." (FORD, 1905e, p. 204)

Seguindo com sua interpretação, para superar tal quadro, o desafio principal dos novos governantes estaria no desenvolvimento da educação e instrução em suas localidades. Apenas elas seriam capazes de promover a saída deste estado de ignorância. Porém, tal medida deveria ser encarada dentro de uma perspectiva de longo prazo, "até que uma nova geração tome lugar, e o que ocorrerá nesse meio tempo não pode ser previsto, nem mesmo você ou eu estaremos vivos para ver." (FORD, 1905e, p. 204)

Na realidade, conforme Jefferson explicou para Du Pont, em sua interpretação, as colônias hispano-americanas ainda não estavam prontas para proclamar sua independência. No âmago de tais sociedades ainda não havia sido desenvolvido o entendimento sobre os seus direitos e, dessa forma, encontravam-se ainda em um estágio atrasado do esclarecimento. Por isso, quando questionou a Humboldt se "seus chefes são suficientemente esclarecidos para formar um governo coeso, e seus povos para assistir a seus chefes?", a resposta que martelava em sua cabeça era apenas uma e havia sido dada a Du Pont: não.

\section{GANPHLAC}

Revista Eletrônica da ANPHLAC, ISSN 1679-1061, №. 22, p. 60-85, Jan./Jun., 2017.

http://revista.anphlac.org.br 
Não podemos deixar de destacar que a leitura de Jefferson sobre o momento é influenciada por um tipo de visão teleológica e de otimismo no "progresso" das sociedades. No caso, as colônias espanholas ainda não haviam chegado na etapa de esclarecimento necessário para que se produzisse a deflagração de uma independência como um fato natural, tal qual, a seu juízo, ocorrera com os Estados Unidos. Estavam ainda num estágio prematuro provocado pelo atraso de seus reis e pela visão limitadora de universo reproduzida pela Igreja Católica. Isso fica evidente em uma nova missiva endereçada a Humboldt dois anos mais tarde, em 06 de dezembro de 1813, onde observava:

\begin{abstract}
Que eles vão se livrar de sua dependência europeia eu não tenho dúvida, mas em que tipo de governo resultará suas revoluções eu não tenho certeza. A história, assim eu creio, não fornece exemplos de povos ordenados por padres que se converteram em governos livres. Isto se configura como o mais baixo grau de ignorância, onde tanto os líderes civis quanto os religiosos conduzem as coisas conforme seus próprios interesses. [...] as diferentes castas entre seus habitantes, o seu ódio mútuo e inveja, a sua profunda ignorância da história, serão pagos por líderes ardilosos, e cada um será feito de instrumento para escravizar aos outros. (JEFFERSON apud TERRA, 1959, p. 793)
\end{abstract}

O resultado de séculos de subjugação, má influência por parte dos padres e da ignorância de seus habitantes não poderia ser outro senão "os despotismos militares". Porém, apesar de assim entender, Jefferson não deixava de se confraternizar com tais povos, uma vez que eles não estariam mais sob as amarras da Europa e seriam, juntamente com os Estados Unidos, "americanos". Apenas a ilustração e o esclarecimento (essa crença genuína que os ilustrados daquele tempo possuíam sobre a educação) poderiam liberta-los das amarras do passado.

De qualquer maneira, anos mais tarde, quando os conflitos no sul pareciam se encaminhar para o fim, Jefferson voltou a se dedicar ao assunto, agora em uma carta enviada para seu grande amigo, o ex-presidente dos Estados Unidos John Adams. Em 22 de janeiro de 1821, comentando sobre o acordo de paz selado seis meses antes entre o Capitão General Pablo Morillo e Simon Bolívar, Jefferson reforçou tudo o que havia dito quase uma década antes:

Eu temia desde o princípio que essas pessoas ainda não estivessem suficientemente esclarecidas para o autogoverno; e que depois de trilhar através do sangue e matança, eles terminassem em tiranias militares, mais ou menos numerosas. No entanto, como eles queriam tentar a experiência, eu desejei-lhes sucesso na mesma. (FORD, 1905f, p. 199)

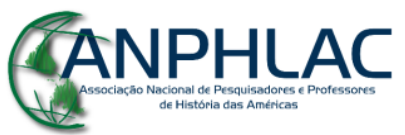

Revista Eletrônica da ANPHLAC, ISSN 1679-1061, №. 22, p. 60-85, Jan./Jun., 2017.

http://revista.anphlac.org.br 
Assim como no princípio, não restou nada para Jefferson além do fato de reafirmar que o único caminho para a superação de tal realidade por parte dos hispanoamericanos estava na educação de seu povo e, da mesma forma como no início dessas cartas, nada do que ele declarasse sobre isso não passava de uma "inconsequente opinião":

\begin{abstract}
possivelmente entenderão que o caminho mais seguro será uma reconciliação com a pátria mãe, que deve mantê-los juntos pela ligação única com o mesmo magistrado-chefe, deixando-lhes energia suficiente para que se mantenham em paz uns com os outros, e para o fortalecimento de seu autogoverno e autoaperfeiçoamento, até que estejam suficientemente treinados pela educação e hábitos de liberdade, para andar com segurança por si mesmos. [...] Veja, meu senhor, como é fácil prescrever aos outros a cura para as suas dificuldades enquanto nós não conseguimos curar as nossas. (FORD, 1905f, p. 199-200)
\end{abstract}

Depois dessa carta, Jefferson voltou a mencionar a situação dos vizinhos em algumas outras. Em 25 de fevereiro de 1822, por exemplo, escreveu para o amigo e expresidente James Madison congratulando-o pelo reconhecimento dado às referidas emancipações e afirmando que, para sua surpresa, elas demoraram muito para se consolidar, uma vez que previa o fim dos combates para três ou quatro anos antes. (FORD, 1905f, p. 227) Em outra oportunidade, em epístola endereçada a James Monroe, agora presidente dos Estados Unidos, em $1^{\circ}$ de dezembro de 1822, lamentou que o Brasil e o México tivessem optado pelo caminho da monarquia, mas que tinha esperanças de que em breve ambos recorressem ao republicanismo como forma de gerir suas nações. (FORD, 1905f, p. 273-274)

Ainda sobre Monroe e o fim das guerras de independência na América Espanhola, chama-nos a atenção um conjunto de correspondências trocadas entre Jefferson e o então presidente dos EUA que se deu entre 1820 e 1824, em um total de seis cartas. A primeira delas é de 14 de maio de 1820. Nela, o ex-presidente aparece preocupado com o futuro de alguns territórios que pertenciam à Espanha, mas que se encontravam sob algum tipo de influência norte-americana, mais especificamente, o Texas. Segundo escreveu, "a província do Techas será o mais rico estado de nossa união, sem nenhuma exceção. [...] As nações europeias dão isso como certo. Nós temos que cuidar de sua ocupação em tempos de paz [...]." (FORD, 1905f, p. 160) ${ }^{16}$ O temor

\footnotetext{
${ }^{16} \mathrm{Na}$ carta, é exatamente assim como aparece a grafia do nome: Techas.

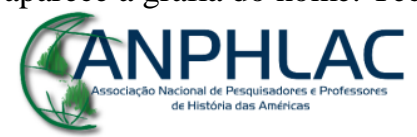

Revista Eletrônica da ANPHLAC, ISSN 1679-1061, №. 22, p. 60-85, Jan./Jun., 2017.

http://revista.anphlac.org.br
} 
de Jefferson era o de que as nações europeias, cientes do potencial econômico que aquelas terras possuíam, resolvessem ocuparem-se delas. Na realidade, temia por uma investida britânica, alterando os acordos sobre o território firmados entre EUA e Espanha, que, agora, possuía um novo governo mais suscetível aos interesses ingleses.

A aproximação dos ingleses à nova administração de Castela provocava calafrios em Jefferson, principalmente quando o assunto era Cuba e isso esteve claro na troca de correspondências com Monroe. Em uma carta de 11 de junho de 1823, Jefferson alertou para o perigo de os ingleses tomarem conta da ilha do Caribe, classificando a intromissão dos britânicos nos assuntos americanos como sendo algo "atroz". Justamente por isso, os EUA deveriam parar de se envolver nas querelas europeias e garantir que os europeus também não se intrometessem nos assuntos do continente. A verdade era que "a posição que as nações europeias ocuparam na América estava desmoronando sobre elas." (FORD, 1905f, p. 293) Enquanto a Europa passava a ser vista como o "território da guerra eterna", em contrapartida, os EUA apareciam a seus vizinhos como a "terra da paz e confraternização". Assim, caso a Inglaterra resolvesse tomar posse de Cuba, deveria o governo norte-americano dar suporte militar aos cubanos no intuito de garantir a sua autonomia. Ainda que não descartasse uma possível anexação de Cuba por parte dos EUA, Jefferson entendia naquele momento que a ilha deveria permanecer sob o domínio espanhol, garantindo sua aproximação diplomática ao mesmo. ${ }^{17}$

O interessante é que pouco mais de dez dias depois de ter enviado essa carta, Jefferson parece ter mudado de ideia, não quanto ao potencial perigo inglês, mas sobre um possível movimento de aproximação dos britânicos em relação a Cuba. Isto aparece em uma nova missiva, enviada no dia 23 de junho. Depois de se encontrar com Mr. Miralla, descrito em sua correspondência como sendo um nativo de Buenos Aires que vivia há pelo menos sete anos em Havana, Jefferson descobriu que suas suspeitas sobre

\footnotetext{
${ }^{17}$ A anexação de Cuba por parte dos EUA era algo que aparecia frequentemente atrelada aos comentários feitos sobre a ilha por parte de Jefferson. O açúcar, seu bom relacionamento comercial com os norteamericanos e o excelente posicionamento geográfico no Caribe eram atrativos que chamavam a atenção do ex-presidente. Alguns meios pelos quais a incorporação da ilha ocorreria também foram aventados nas epístolas, conforme vemos aqui, em correspondência direcionada a Monroe em 23 de junho de 1823: "É melhor, então, permanecer de prontidão para receber o interesse pela incorporação quando isso for solicitado por ela [Cuba] mesma. Pois, certamente, a sua adição à nossa confederação é exatamente o que falta para que se complete o nosso poder como uma nação, ao ponto que mais interessa." (FORD, 1905f, p. 298)
}

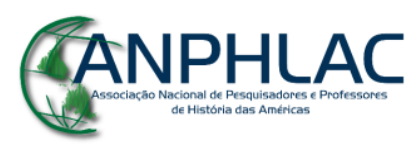

Revista Eletrônica da ANPHLAC, ISSN 1679-1061, №. 22, p. 60-85, Jan./Jun., 2017.

http://revista.anphlac.org.br 
os interesses ingleses não passavam de um grande equívoco. Por aquilo que ele conseguiu apurar, não havia o menor interesse entre os cubanos de se juntarem ao império britânico e que todos estavam satisfeitos com a condição atual da ilha. No entanto, caso Cuba viesse a se incorporar a alguma nação em seu futuro, essas seriam, preferencialmente, os EUA ou o México. Sendo assim, “como não há perigo de que ela [Cuba] caia nos domínios da Inglaterra, eu devo retificar uma opinião fundada em um fato equivocado." (FORD, 1905f, p. 298)

O que essas cartas deixam transparecer é a leitura de Jefferson sobre os novos contornos políticos e geográficos que se desenhavam no continente e como isso poderia alterar os interesses dos Estados Unidos na região. Mais, se a Inglaterra teria como se estabelecer enquanto uma força hegemônica no hemisfério americano, aproveitando o enfraquecimento da França e da Espanha, com o final das guerras de independência na América e os conflitos nacionais na Europa. Justamente por isso, os EUA poderiam “incentivar a independência de Cuba contra qualquer país no mundo, à exceção da Espanha.” (FORD, 1905f, p. 293) ${ }^{18}$ A preocupação de Jefferson era evitar a perda dos territórios espanhóis agora ocupados por colonos norte-americanos, como o Texas, e impedir que a Inglaterra se instalasse na ilha do Caribe, adquirindo o controle marítimo da região. Para tanto, deveria manter boas relações diplomáticas como os ibéricos.

É sobre isso também que tratam as duas últimas cartas endereçadas a Monroe no ano de 1823: como os EUA deveriam se portar junto às nações europeias agora que quase a totalidade do continente encontrava-se emancipado. O que Jefferson não sabia, mas agora nós sabemos, é que o então presidente colhia junto a ele e a Madison conselhos sobre qual deveria ser o posicionamento dos EUA diante do novo cenário internacional que emergira no primeiro quartel do século XIX. Ambos sugeriram que o caminho não era o enfrentamento com a Inglaterra, mas uma composição de forças. Ao que tudo indica, Monroe resolveu tomar um caminho diverso e, nos primeiros dias de dezembro de 1823, proclamaria junto ao Congresso aquilo que se convencionou chamar de Doutrina Monroe. De qualquer maneira, ainda que seus conselhos não tenham sido acolhidos, essas cartas compõem uma parte importante de um dos capítulos mais decisivos nas relações entre os Estados Unidos e a América Latina.

\footnotetext{
${ }^{18}$ A independência de Cuba e a participação da Inglaterra na mesma também foram temas de uma carta escrita por Jefferson a William Short em 28 de março de 1823. (FORD, 1905f, p. 281-286)
}

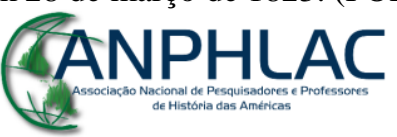

Revista Eletrônica da ANPHLAC, ISSN 1679-1061, №. 22, p. 60-85, Jan./Jun., 2017.

http://revista.anphlac.org.br 
Jefferson escreveu essas cartas a Monroe sempre se colocando como um "humilde" conselheiro que apenas respondia aos questionamentos do amigo, sem querer se intrometer nos negócios da presidência. Ainda que as cartas analisadas neste segundo item tenham sido autoclassificadas como "opiniões sem propósitos" ou "conselhos de alguém desatualizado", é evidente que elas foram um importante instrumento para a construção de redes de sociabilidade pelas quais o posicionamento político e a presença do ex-presidente não deixassem de existir, ainda que ele não estivesse mais no cotidiano da política, embora representado por suas missivas.

\section{Referências Bibliográficas}

COHEN, William. Thomas Jefferson e o Problema da Escravidão. Estudos Avançados, n. 14 (38), 2000, p. 151-180.

EGERTON, Douglas. Gabriel's Rebellion: The Virginia Slave Conspiracies of 1800 and 1802. Durham: University of North Carolina Press, 1993.

FORD, Paul Leicester (Org.). The Works of Thomas Jefferson. Vol. VI. New York/London: G. P. Putnam's Sons/The Knickerbocker Press, 1905a.

. The Works of Thomas Jefferson. Vol. VII. New York/London: G. P. Putnam's Sons/The Knickerbocker Press, 1905 b.

. The Works of Thomas Jefferson. Vol. VIII. New York/London: G. P. Putnam's Sons/The Knickerbocker Press, 1905c.

The Works of Thomas Jefferson. Vol. IX. New York/London: G. P. Putnam's Sons/The Knickerbocker Press, 1905 d.

. The Works of Thomas Jefferson. Vol. XI. New York/London: G. P. Putnam's Sons/The Knickerbocker Press, 1905e.

The Works of Thomas Jefferson. Vol. XII. New York/London: G. P. Putnam's Sons/The Knickerbocker Press, $1905 f$.

HICKEY, Donald R. America's Response to the Slave Revolt in Haiti, 1791-1806. Journal of the Early Republic, Vol. 2, No. 4 (Winter, 1982), p. 361-379.

KILMEADE, Brian; YAEGER, Don. Thomas Jefferson and the Tripoli Pirates: The Forgotten War That Changed American History. New York: Sentinel, 2015.

\section{GANPHLAC}

Revista Eletrônica da ANPHLAC, ISSN 1679-1061, №. 22, p. 60-85, Jan./Jun., 2017.

http://revista.anphlac.org.br 
LOCKHART, James; SCHWARTZ, Stuart B. A América Latina na Época Colonial. Rio de Janeiro: Civilização Brasileira, 2002.

LOKKE, Carl Ludwig. Jefferson and Leclerc Expediction. The American Historical Review, Vol. 33, No. 2 (Jan., 1928), p. 322-328.

LYNCH, John. As origens das independências da América Espanhola. In: BETHELL, Leslie (Org.). História da América Latina. Vol. III. São Paulo: Edusp; Brasília, DF: Fundação Alexandre Gusmão, 2004, p. 19-72.

MATTHEWSON, Tim. Jefferson and Haiti. The Journal of Southern History, Vol. 61, No. 2 (May, 1995), p. 209-248. . Jefferson and the Nonrecognition of Haiti. Proceedings of the American Philosophical Society, Vol. 140, No. 1 (Mar., 1996), p. 22-48.

PARET, Peter. Jefferson and the Birth of European Liberalism. Proceedings of the American Philosophical Society, Vol. 137, No. 4, 250th Anniversary Issue (Dec., 1993), p. $488-497$.

PECEQUILO, Cristina Soreanu. A política externa dos Estados Unidos. $2^{\mathrm{a}}$ ed. Porto Alegre: Editora UFRGS, 2005.

SCHWABACH, Aaron. Thomas Jefferson, Slavery, and Slaves. Thomas Jefferson Law Review, Vol. 33:1, 2010, p. 1-60.

TERRA, Helmut. Alexander von Humboldt's Correspondence with Jefferson, Madison, and Gallatin. Proceedings of the American Philosophical Society, Vol. 103, No. 6, Studies of Historical Documents in the Library of the American Philosophical Society (Dec. 15, 1959), p. 783-806.

\section{GANPHLAC}

Revista Eletrônica da ANPHLAC, ISSN 1679-1061, №. 22, p. 60-85, Jan./Jun., 2017. http://revista.anphlac.org.br 